anales de psicología, 2018, vol. 34, n 2 (may), 299-304 http://dx.doi.org/10.6018/analesps.34.2.283771
(C) Copyright 2018: Editum. Servicio de Publicaciones de la Universidad de Murcia. Murcia (Spain) ISSN print edition: 0212-9728. ISSN web edition (http://revistas.um.es/analesps): 1695-2294

\title{
Emotional Intelligence and its role in Cognitive Flexibility of Children with and without Attention Deficit Hyperactivity Disorder
}

\author{
Seyed Amir Amin Yazdi*, Seyedeh Maryam Moshirian Farahi, Seyed Mohammad Mahdi Moshirian Farahi, \\ and Javad Hosseini
}

Ferdowsi University of Mashbad, Islamic Azad University, Torbat-e-Jam (Iran)

\begin{abstract}
Título: Inteligencia emocional y su papel en la flexibilidad cognitiva de niños con y sin trastorno por déficit de atención con hiperactividad.

Resumen: El objetivo de este estudio fue comparar el papel de la inteligencia emocional en la flexibilidad cognitiva de niños con y sin trastorno por déficit de atención e hiperactividad (TDAH). Los participantes fueron 20 niños (edad promedio $=10.25, D T=2.12)$ con TDAH y 30 niños normales (edad promedio $=10.96, D T=1.32$ ) que todos eran niños. Todos los participantes completaron el Cuestionario de inteligencia emocional (Schutte et al., 1998) y la prueba clásica de Stroop, como una medida de la flexibilidad cognitiva. Los niños con TDAH se desempeñaron peor en ambas medidas que los niños sin TDAH. Y predictores de inteligencia emocional de la flexibilidad cognitiva en dos grupos. En general, en niños con déficit de atención - trastorno de hiperactividad hay bajo rendimiento de inteligencia emocional y flexibilidad cognitiva.

Palabras clave: inteligencia emocional; flexibilidad cognitiva; déficit de atención; desorden de hiperactividad.
\end{abstract}

\begin{abstract}
The aim of this study was to compare role of emotional intelligence in cognitive flexibility of children with and without Attention Deficit Hyperactivity Disorder (ADHD). Participants were 20 children (mean age $=10.25, S D=2.12$ ) with ADHD and 30 normal children (mean age $=$ $10.96, S D=1.32$ ) that all of they were boy. All participants completed the Emotional Intelligence Questionnaire (Schutte et al., 1998) and the classic Stroop test, as a measure of cognitive flexibility. ADHD children performed poorer on both measures than non-ADHD children. And emotional intelligence predictors of cognitive flexibility in two groups. Overall, in children with attention deficit - hyperactivity disorder there are low performance of emotional intelligence and cognitive flexibility.

Keywords: Emotional intelligence; cognitive flexibility; attention deficit; hyperactivity disorder.
\end{abstract}

\section{Introduction}

Attention-deficit hyperactivity disorder (ADHD) has been known as a neurodevelopmental disorder. According to DSM-5, the prevalence rate of this disorder in most cultures is about $5 \%$ in children and $2.5 \%$ in adults (American Psychiatric Association, 2013). It is characterized by pervasive attention deficit disorder, hyperactivity and impulsivity, which often merge together and form a whole complex (Rabiner, Murray, Skinner, \& Malone, 2010).

Children with ADHD have interpersonal problems and dysfunctional social behavior and poor academic performance (Bresnahan, Anderson, \& Barry, 1999).

Longitudinal studies on preschool children with ADHD suggest that this disorder remains almost unchanged in various areas over time and a large proportion of preschool children are at risk of ADHD in the future (Rajendran et al., 2013). These children have trouble in areas such as future planning, problem solving and behavioral problems. The behavioral traits are often associated with frontal cortex disorders, especially prefrontal, basal nuclei and limbic system (Curatolo, D'Agati, \& Moavero, 2010).

Some studies on the causes of ADHD have primarily focused on biological and genetic factors (Barkley, 2003) identifying a series of factors such as biological and environmental risk factor that lead to the emergence of these symptoms over time. Since ADHD is a complex chronic, cerebral, developmental and behavioral disorder, any explanation as to the causes of this disorder that lends itself to a single cause will probably fail to provide a comprehensive

* Correspondence address [Dirección para correspondencia] Seyed Amir Amin Yazdi. Ferdowsi University of Mashhad, Mashhad (Iran). E-mail: yazdi@um.ac.ir picture of this disorder (Curatolo, D'Agati, \& Moavero, 2010). One theory about the causes of this disorder is Barkley's theory according to which children with ADHD are characterized by impaired performance in executive functions. These functions refer to metacognitive functions responsible for a set of abilities such as inhibition, selfinitiation, strategic planning, cognitive flexibility and impulse control. In fact, functions such as organization, decision-making, cognitive flexibility, working memory, maintenance and shift, motor control, time sensation and perception, future prediction, reconstruction, internal language and problem solving are key executive neurological functions that help humans in their daily life and implementation of learning tasks and cognitive activities (Barkley, 1998). The relationship between executive functions and various behavioral, cognitive, social, and communication dimensions have been investigated in several studies.

Any impairment of executive functions can have detrimental effect on these dimensions (Gray et al., 2012; and Familiar, et al., 2015). A key element of Barkley's theory is related to defective emotional regulation (Hallahan, Kauffman \& Pullen, 2011). According to the Barkley's theory, emotional problems and cognitive flexibility of children with ADHD is rooted in inhibition impairment. As such, behavioral impairment can prepare the ground for executive dysfunctions, time perception and management, thereby undermining one's ability to engage in purposive actions.

According to Barkley's theory, emotion regulation and stability requires perfect executive functions in individuals, but children and adults with ADHD have problem regulating their emotions. In Barkley's theory, there is special emphasis on cognition, and emotions are treated as a peripheral factor. In contrast, the transformational model of 
individual differences, which is based on communication, stresses the role of emotions in human's psychological growth, posits that all basic abilities of human beings are not predefined genetic features that emerge over the development process, but rather a series of acquired capabilities that develop and transform within a child's emotional relationships with others (Hallahan, Kauffman \& Pullen, 2011).

Biopsychosocial approach in which the quality of interaction between biological characteristics in each child together with parenting style determines healthy condition or emergence of transformation disorder in children (Amin Yazdi, 2012). Based on Greenspan's model (the developmental, individual-difference, relationship-based model, DIR), if over- sensitiveness of a child is accompanied with aggressive and controlling parenting style, the child will be susceptible to anxiety disorders. However, the same biological trait, if associated with a comforting and dialogue-based parenting styles, will help a child develop mental growth in commensurate with his age (Greenspan \& Greenspan, 2009). From Greenspan's theory, emotions are assumed to be responsible for the emergence of cognition, reflection, morality, self- awareness and creativity (McMillan, 2006). In fact, some studies have shown that the high emotional intelligence had a better performance in prefrontal cortex task (Alipour, Arefnasab \& Babamahmoodi, 2011). In this study we investigate emotional intelligence and cognitive flexibility in ADHD children.

Many studies have investigated cognition and emotions in patients with ADHD separately. For example, the role of executive functions and cognitive factors has been investigated in a number of studies, e.g., dos Santos Assef, Capovilla, and Capovilla (2007) examined performance on the classic Stroop test in children with ADHD, finding that they had impaired performance in selective attention and reaction time. The theory of defective executive functions (EF) in this disorder has been proposed and supported by a number of studies (Nigg, 2006, Vinogradov, Fisher, de Villers-Sidani, 2010).

There are several studies in support of Barkley's theory. For instance, Sachjog Velez (2009) showed that children with ADHD had defective executive function. Rapport, Orban, Kofler, \& Friedman (2013) reported that children with ADHD had impaired cognitive functions and working memory and were attention deficient. Bledsoe, SemrudClikeman, Pliszka (2010) demonstrated that people with ADHD had problem in response inhibition. Alderson, Rapport, Hudec, Sarver and Kofler (2010) in a study on working memory and inhibition in children with ADHD revealed their dysfunction in working memory and behavioral inhibition. Mashhadi, Rasoulzadeh-Tabatabaie, Azadfallah and Soltanifar (2009) in their study on 45 children with ADHD and 15 normal children found that the former had weaker performance in Stroop test compared to the normal children.

Scheres et al. (2004) emphasized the role of emotion in their study, asserting that children with ADHD display ex- cessive negative emotions in their interpersonal relationships and tend to be highly impulsive. Also, they were unable to take advantage of their emotion to moderate other emotions. In the study of Amni- Khanavandi (2008), a significant difference was observed between emotional intelligence and emotional instability of normal students and students with ADHD. According to the results of this study, students with ADHD had significant trouble in terms of emotional intelligence (EI) and EI stability (based on Salovey and Mayer model of emotional intelligence), a point that should be taken into account in the treatment and diagnosis of this disorder. Walcott and Landau (2004) in a study on 49 male children (aged 6-11 years) with and without ADHD found that children with ADHD scored lower in emotional self-regulation.

A review of the literature suggests a shortage of studies on the interaction of emotion and executive functions (cognition) and their interrelation. The focus of this study is on DIR approach (Greenspan \& Greenspan, 2009) and the primacy of emotion over cognition. Thus, the main goal of the present study is to compare children with ADHD in terms of cognitive flexibility compared to normal children as well as the relationship between emotional intelligence and cognitive flexibility as an executive function. In this study, the following three hypotheses have been assumed: (a): Children with ADHD have weaker cognitive flexibility compared to non-ADHD children. (b): Children with ADHD have lower emotional intelligence compared to the normal children. (c): Emotional intelligence is a predictor of cognitive flexibility.

\section{Methods}

\section{Participants}

The study population consisted of boys aged 8-14 years with ADHD in the city of Mashhad in the year 2014. The sample population was selected using available sampling method. Participants, after obtaining permissions from their parents, were chosen on a voluntary basis from Ebne Sina Hospital $(n=20)$. Inclusion criteria were the diagnosis of ADHD by a clinical psychologist or a psychiatrist, an age of 8-14 years, male gender and completion of informed consent form to participate in this study. Moreover, 30 normal children who matched the experiment group in terms of gender and age were selected from among the primary school students in the District One of Mashhad using cluster sampling method.

The inclusion criteria of normal children were: no history of psychiatric disorders, male gender, age between 8 and 14 years and the completion of informed consent form to participate in the study. 


\section{Instruments}

1. Schutte Self-Report Emotional Intelligence Test (SSEIT): this short self-report scale, which was developed by Schutte et al. (1998). We used the SSEIT because the SSEIT is structured off of the EI model by Salovey and Mayer (1990). The SSEIT model is closely linked with the EQ-I model of Emotional Intelligence. This test consisted of 33 items and uses a 5-point Likert scale (form strongly agree to strongly disagree) to evaluate responses.

This scale includes total score and 3 subscales, though in some studies 4 subscales have been reported. These subscales include emotion regulation, social skills, emotion assessment and expression and utilizing emotions (Salovey, Brackett, \& Mayer, 2004). In a study by Austin, Evans, Goldwater and Potter (2005) to evaluate this test on a sample of Canadian students, an internal validity of $0.72,0.73$ and 0.71 were obtained for three factors of emotion regulation, emotion assessment and expression and utilizing emotion respectively and a reliability coefficient of 0.84 was reported for the total score. In Iran, this questionnaire was normalized by Khosrow Javidi (2002) and a reliability coefficient of 0.81 was reported.

2. Computerized Stroop Test: Classic Stroop test was developed by John Ridley Stroop (Stroop, 1935). Since then, the test has been widely used as a measure of selective attention and cognitive flexibility. The classic Stroop test is one of the main tests used to measure response inhibition. In the test, 50 color words consistent with the meaning of the words (i.e., congruent words) were used (red, yellow, green and blue). Moreover, 50 color words that were written in a color that were inconsistent with the meanings of the words (incongruent) (blue in red) were used. There was an interval of stimulus presentation time of $800 \mathrm{~ms}$ and $3000 \mathrm{~ms}$ stimulus presentation between the stimuli. The test requires participants to ignore the meaning of the words and only respond to the ink color in which a word appears (Savitz \& Jansen, 2003). In order for scoring and interpreting the results, reaction time scores are calculated separately for each group of words (congruent and incongruent) and the number of error and correct responses are also calculated. Interference score is calculated by subtracting mean RTs to congruent words from mean RTs to incongruent words. Research conducted on the classic Stroop test represents a reliable and valid measure of inhibition in both adults and children. Retest reliability of this test in the range of .80 to .91 has been reported (Mashhadi et al., 2009).

\section{Procedure}

After selecting samples and obtaining informed consent for participation in the study, the EI test was administered to participants followed by Stroop test. The group of normal children was selected using random cluster sampling form among primary school children in District 1 of Mashhad. Before administering the Stroop test, an education explained test instructions to participants. For the purpose of practicing and familiarizing children with keyboard and test process prior to the main color-word test, 40 colored stars were shown to children. After the orientation session for introducing subjects to the test, the main test was run in which subjects were required to respond to colors of words irrespective of their meaning. The computer calculated the exact reaction time of each participant when responding to words as well as the number of correct and wrong responses related to each individual.

\section{Statistical Analysis}

Data analysis was conducted using SPSS 20 and comparative tests of central tendencies for two dependent and independent groups, along with correlation and regression tests.

\section{Results}

There were 30 subjects in the normal group and 20 subjects in the ADHD group with a mean age of 8 to 14 years. The normal and ADHD groups had a mean age of 10.96 and 10.25 years with a standard deviation of 1.32 and 2.12 respectively.

As shown in Table 1, the mean error rate of the classic Stroop test in children with ADHD was greater than normal children, and the two groups were significantly different in this regard $(p<0.05)$. Also, the average number of correct answers in children with ADHD was lower than normal children $(p<.05)$. An interference score of 186.62 was obtained by children with ADHD, which was significantly larger from the mean interference score of normal children $(60.33)(p<.05)$.

Table 1. Descriptive indexes in Classical Stroop Task in ADHD and Normal Children, and Results of Independed $t$-test.

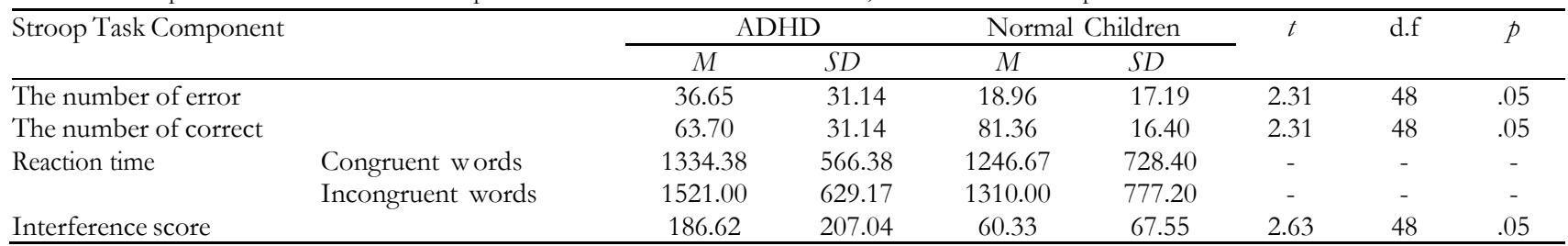


Table 2. Descriptive indexes in Emotional Intelligence in ADHD and Normal Children, and Results of Independed $t$-test.

\begin{tabular}{|c|c|c|c|c|c|c|c|}
\hline \multirow{2}{*}{$\begin{array}{l}\text { Emotional Intelligence } \\
\text { Component }\end{array}$} & \multicolumn{2}{|c|}{ ADHD } & \multicolumn{2}{|c|}{ Normal Children } & \multirow[t]{2}{*}{$t$} & \multirow[t]{2}{*}{ d.f. } & \multirow[t]{2}{*}{$p$} \\
\hline & $M$ & $S D$ & $M$ & $S D$ & & & \\
\hline Emotional regulation & 39.20 & 6.12 & 48.73 & 8.51 & 4.60 & 48 & .01 \\
\hline Emotional assessment & 26.75 & 3.35 & 27.80 & 4.78 & 0.85 & 48 & - \\
\hline Social skills & 34.70 & 6.69 & 37.16 & 6.15 & 1.34 & - & - \\
\hline Utilizing emotion & 16.35 & 3.85 & 20.30 & 4.17 & 3.37 & 48 & .01 \\
\hline Emotional Intelligence total score & 117.00 & 14.17 & 134.00 & 17.66 & 3.59 & 48 & .01 \\
\hline
\end{tabular}

Table 3. The correlation between emotional intelligence and cognitive flexibility.

\begin{tabular}{lll}
\hline Emotional Intelligence & ADHD & Normal children \\
\hline Cognitive flexibility & $-.69 * *$ & -.23 \\
\hline$* * p<.01$ &
\end{tabular}

$* * p<.01$

Table 4. ANOVA and Regression results.

\begin{tabular}{lcccccc}
\hline & Sum of squares & d.f. & Means of squares & F & R & $\mathrm{R}^{2}$ \\
\hline Regression & 315591.32 & 4 & 78899.33 & 4.31 & 0.52 & 0.27 \\
Residual & 822601.07 & 45 & 18280.023 & & 0.01 \\
Total & 1138198.39 & 49 & & & \\
\hline
\end{tabular}

\section{Discussion}

The aim of this study was to compare two variables of EI and cognitive flexibility in two groups of children with ADHD and normal children. The first hypothesis, i.e., children with ADHD display lower performance in cognitive flexibility in comparison to normal children, was confirmed with the results of this study. That is, children with ADHD had weaker performance in Stroop computer test which measures cognitive flexibility.

This is consistent with the findings of Tehrani Doost, Radgoodarzi, Sepasi, Alaghebandrad (2003), Mashhadi et al (2009) and Savitz and Jansen (2003). Considering that this test analyzes the function of frontal lobe, the results were in agreement with the findings of Shu and Douglas, (1992) and Aman, Roberts, and Pennington (1998). Farrant, Fletcher and Maybery (2014) examined the relationship between cognitive flexibility and ADHD using dimensional change card sort (DCCS). The findings suggested a significant negative relationship between cognitive flexibility and ADHD.

In another study, Bálint, Bitter and Czobor (2015) investigated the relationship between brain areas and cognitive flexibility in subject with ADHD form a biological perspective. They reported that subjects with ADHD suffered from low functioning in prefrontal, parietal and basal ganglia areas, which was associated with reduced functioning of the cognitive flexibility.

The second hypothesis, i.e., children with ADHD had lower EI compared to normal children, was also approved by the findings. Children with ADHD had weaker performance in all factors of EI including emotion regulation, emotion assessment, social skills, utilizing emotion and total EI compared to normal children, which was consistent with Barkley's theory.
This is consistent with the findings of Hashemi Nosrat Abadi, Mahmoud Alilou, Ne'mati Sougi Tapeh and Gholam Rostami (2010) according to which children with ADHD had impaired functioning in emotion self-regulation and motivation. This is also in agreement with the study of Behrouz, Aliabadi, Yazdkhasti and Vaisi (2012).

Generally, the results of the comparison of two groups revealed that children with ADHD were significantly different from normal children in two variables of cognitive flexibility and EI. This difference is primarily due to the defective neuropsychological system of children with ADHD. The primary problem of these children is defective inhibition process (Mashhadi et al., 2009), as behavioral inhibition disorder leads to the impairment of executive functions, time awareness and management, thereby hampering the ability of a person to engage in sustainable purposive actions.

In Barkley's model, individuals with ADHD have trouble in four main areas of executive function including deficient working memory, delayed internal speech, impaired control of excitation levels and emotion regulation. They also tend to act dramatically in face of extreme negative or positive experiences. For example, when children with ADHD hear good news, they may cry loudly, unable to control their emotion. In addition, they feel immediately frustrated and angry in front of failing experiences. In the same vein, children and adults with ADHD are defective in analyzing problems and transferring solutions to others (Hallahan, Kauffman, Pullen, 2011). According to the third hypothesis, i.e. El is a predictor of cognitive flexibility, EI can explain $27 \%$ of variation in cognitive flexibility. As we know, impaired cognitive executive functions such as planning, problem solving and cognitive flexibility can cause problems and disrupt interpersonal relationships (Zelazo, Muller, Frye, \& Marcovitch, 2003). As a key factor in interpersonal 
relations, EI describes how a person perceives other people's emotions or manage to control his emotions in face of any conflict or problem (Moshirian Farahi, Asghari Ebrahimabad, Moshirian Farahi, Razaghi Kashani, \& Tavakoli, 2016). The main issue concerning children with ADHD is their inability to establish relationship with their peers, which is rooted in their deficiency in organizing and regulating emotions and behaviors (Hallahan, Kauffman, \& Pullen, 2011). In the DIR approach, there is much emphasis on the role of emotions. In contrast to views that believe in cognitive and emotional balance or the primacy of cognition over emotion, it posits that emotion is a predictor of cognition, reflection, self- awareness and creativity.

The elements of human's mind including senses, movements, attention and memory are controlled and organized by emotion. By providing purpose for a behavior, emotion coordinates different parts of organisms, and thus gives meaning to personal experiences. Emotions also lay the foundation upon which mental representations, ideas and linguistic symbols are built, which are later used in streams of imagination, reflection and logical and abstract reasoning.

There are a host of research evidences about the role of emotion in human healthy and non-adaptive functions (Pessoa, 2011; Waring \& Kensinger, 2011) with studies on EI revealing that EL is an effective and decisive factor in real life events such as school success and academic achievement, career success, interpersonal relationships, and in general, physical and psychological health (Mayer, Salovey, \& Caruso, 2008; Zeidner, Matthews, \& Roberts, 2009).

According to the results of this study relation to the role of EI as a predictor of cognitive flexibility, EI teaching should be incorporated in emotion related interventions. EI training can be effective through direct instruction to children or teaching their parents how to deal with these children. In general, executive functions, especially the one discussed in this study, namely cognitive flexibility, is a major variable in children with ADHD. As we know, EI is a key

\section{References}

Alderson, R. M., Rapport, M. D., Hudec, K. L., Sarver, D. E., \& Kofler, M. J. (2010). Competing core processes in attention-deficit/hyperactivity disorder (ADHD): do working memory deficiencies underlie behavioral inhibition deficits?. Journal of Abnormal Child Psychology, 38(4), 497507.

Alipour, A., Arefnasab, Z., \& Babamahmoodi, A. (2011). Emotional Intelligence and Prefrontal Cortex: A Comparative Study Based on Wisconsin Card Sorting Test (WCST). Iranian journal of psychiatry and behavioral sciences, $5(2), 114$.

Aman, C. J., Roberts Jr, R. J., \& Pennington, B. F. (1998). A neuropsychological examination of the underlying deficit in attention deficit hyperactivity disorder: frontal lobe versus right parietal lobe theories. Developmental psychology, 34(5), 956.

American Psychiatric Association. (2013). Diagnostic and statistical manual of mental disorders (DSM-5®). American Psychiatric Pub.

Amin Yazdi, A. (2012). The developmental, individual-difference, relationship-based model (DIR). Foundation of Education, 2(1), 109-126.

Amni-Khanavandi, M. (2009). The relationship of emotional intelligence and emotional instability among students with and without attention deficit byperactivity. factor in emotion regulation, emotion expression and how these individuals cope with their surrounding environment. That is, EI can enhance the cognitive flexibility of children with ADHD, which is another evidence for the significant effect of emotions over cognition.

One therapeutic outcome of this study for improving emotional and cognitive problems in children with ADHD is the use of techniques and approaches based on DIR, which is due to the special emphasis placed on emotions in the transformational model. The transformation model of interpersonal differences is based on an emphasis on the role of emotional interactions in the development of human cognitive ability according to which all basic human abilities are not merely predefined genetic features that emerge during the growth process, but rather acquired capacities developed and evolved through the interaction of children with others. This approach stresses the emergence of emotions in relationships and treats emotions as the leading cause of cognition, reflection, morality, self-awareness and creativity (Amin Yazdi, 2012). Accordingly, DIR transformation model can be one of the effective therapeutic approach in improving the emotional and consequently cognitive flexibility.

\section{Conclusion}

Low EI function and cognitive flexibility in children with ADHD can be a predictor of these children's problems in social, relational and finally emotional and cognitive domains. The results of this research can be useful for clinical and educational specialists and parents of these children as it highlights the importance of EI and cognitive training in children with ADHD.

Acknowledgments.- The research was approved and funded by Ferdwosi University of Mashhad, Iran (Project Code: 2/28264).

Personality Psychology Master's thesis. Azad University of Karaj, Karaj, Iran.

Austin, E. J., Evans, P., Goldwater, R., \& Potter, V. (2005). A preliminary study of emotional intelligence, empathy and exam performance in first year medical students. Personality and Individual Differences, 39(8), 1395-1405.

Barkley, R. A. (Ed.). (1998). Attention-deficit byperactivity disorder: A bandbook for diagnosis and treatment. New York: The Guilford Press.

Barkley, R. A. (2003). Issues in the diagnosis of attentiondeficit/hyperactivity disorder in children. Brain and development, 25(2), 77-83.

Bálint, S., Bitter, I., \& Czobor, P. (2014). Neurobiological correlates of cognitive flexibility in ADHD-A systematic review of the literature. Psychiatria Hungarica: A Magyar Pszichiatriai Tarsasag tudomanyos folyoirata, 30(4), 363-371.

Behrouz, B., Aliabadi, SH., Yazdkhasti, F., Vaisi, S. (2012). Children with Attention Deficit Hyperactivity Disorder and normal compared to the two categories of emotional intelligence and attachment styles. Research in Rehabilitation Sciences, 8(6), 1032-1044. 
Bresnahan, S. M., Anderson, J. W., \& Barry, R. J. (1999). Age-related changes in quantitative EEG in attention-deficit/hyperactivity disorder. Biological psychiatry, 46(12), 1690-1697.

Bledsoe, J. C., Semrud-Clikeman, M., \& Pliszka, S. R. (2010). Response inhibition and academic abilities in typically developing children with attention-deficit-hyperactivity disorder- combined subtype. Archives of clinical neuropsychology, acq048.

Curatolo, P., D'Agati, E., \& Moavero, R. (2010). The neurobiological basis of ADHD. Italian journal of pediatrics, 36(1), 1.

dos Santos Assef, E. C., Capovilla, A. G. S., \& Capovilla, F. C. (2007). Computerized Stroop test to assess selective attention in children with attention deficit hyperactivity disorder. The Spanish journal of psychology, 10(01), 33-40.

Familiar, I., Ruisenor-Escudero, H., Giordani, B., Bangirana, P., Nakasujja, N., Opoka, R., \& Boivin, M. (2015). Use of the Behavior Rating Inventory of Executive Function and Child Behavior Checklist in Ugandan Children with HIV or a History of Severe Malaria. Journal of developmental and behavioral pediatrics: JDBP, 36(4), 277-284.

Farrant, B. M., Fletcher, J., \& Maybery, M. T. (2014). Cognitive flexibility, theory of mind, and hyperactivity/inattention. Child development research, 2014, Article ID 741543. http://dx.doi.org/10.1155/2014/741543

Gray, S. A., Chaban, P., Martinussen, R., Goldberg, R., Gotlieb, H., Kronitz, R., ... \& Tannock, R. (2012). Effects of a computerized working memory training program on working memory, attention, and academics in adolescents with severe LD and comorbid ADHD: a randomized controlled trial. Journal of Child Psychology and Psychiatry, 53(12), $1277-1284$.

Greenspan, S. I. (2009). Overcoming Anxiety, Depression and other Mental Health Disorders in Children and Adults: A New Roadmap for Families and Professionals. Bethesda, Maryland: Interdisciplinary council on developmental and learning disorders.

Hallahan, D. P., Kauffman, J. M., \& Pullen, P. C. (2011). Exceptional learners: An introduction to special education. Upper Saddle River, NJ: Pearson.

Hashemi Nosratabad, T., Mahmoud Alilou, M., Ne'mati Sougi Tapeh, F \& Gholam Rostami, H.A., (2010). Comparison of self-regulation of Emotional and Motivational Executive Functions in Subtypes of Attenti on-Deficit / Hyperactivity Disorder Based on Barkley's Model. Advances in Cognitive Science, 12(1), 1-16.

Khosrow Javidi, M. (2002). Verifying the Reliability and validity of emotional intelligence, shooting, MA thesis. Tarbiat Modares University, Tehran, Iran.

Mashhadi, A., Rasoulzadeh-Tabatabaie, K., Azadfallah, P., \& Soltanifar, A. T. E. F. E. H. (2009). The comparison of response inhibition and interference control in ADHD and normal children. Journal of Clinical Psycology, 1(2), 0-0.

Mayer, J. D., Salovey, P., \& Caruso, D. R. (2008). Emotional intelligence: new ability or eclectic traits?. American psychologist, 63(6), 503.

McMillan, D.W. (2006). Emotion rituals: A resource for therapists and clients. Taylor \& Francis Group.

Moshirian Farahi, S. M. M., Asghari Ebrahimabad, M.J, Moshirian Farahi, S.M., Razaghi Kashani, SH. \& Tavakoli, H. (2016). The relationship between the religious attitudes with marital satisfaction and psychological health and resilience in prison officer. Journal of Reaserch on Religion \& Health, 2(2), 24-33.

Mueller, S. C. (2011). The influence of emotion on cognitive control: relevance for development and adolescent psychopathology. Cognitive and affective control, 111.

Nigg, J.T. (2006). What causes ADHD Understanding What Goes Wrong and Why. New York: The Guilford Press.

Pessoa, L. (2010). Emotion and cognition and the amygdala: from "what is it?" to "what's to be done?". Neuropsychologia, 48(12), 3416-3429.
Rabiner, D. L., Murray, D. W., Skinner, A. T., \& Malone, P. S. (2010). A randomized trial of two promising computer-based interventions for students with attention difficulties. Journal of abnormal child psychology, 38(1), 131-142.

Rajendran, K., Trampush, J. W., Rindskopf, D., Marks, D. J., O’Neill, S., \& Halperin, J. M. (2013). Association between variation in neuropsychological development and trajectory of ADHD severity in early childhood. American Journal of Psychiatry, 170(10), 1205-1211.

Rapport, M. D., Orban, S. A., Kofler, M. J., \& Friedman, L. M. (2013). Do programs designed to train working memory, other executive functions, and attention benefit children with ADHD? A meta-analytic review of cognitive, academic, and behavioral outcomes. Clinical psychology review, 33(8), 1237-1252.

Sachjog Velez, S.M. (2009). Relationships between Executive Functions, Attention Deficit Hyperactivity Disorder (ADHD), Comorbid Disorders, and Familial History in a Nonclinical Population. Submitted in Partial Fulfillment of the Requirements of the Degree of Doctor of Psychology, Department of Psychology, Philadelphia College of Osteopathic Medicine.

Salovey, P. \& Mayer. J. D. (1990). Emotional intelligence. Imagination, Cognition and Personality, 9, 185-211.

Salovey, P., Brackett, M. A., \& Mayer, J. D. (Eds.). (2004). Emotional intelligence: Key readings on the Mayer and Salovey Model. Portchester, New York: National Professional Resources.

Savitz, J. B., \& Jansen, P. (2003). The Stroop Color-Word Interference Test as an indicator of ADHD in poor readers. The Journal of genetic psychology, 164(3), 319-333.

Scheres, A., Oosterlaan, J., Geurts, H., Morein-Zamir, S., Meiran, N., Schut, H., ... \& Sergeant, J.A. (2004). Executive functioning in boys with ADHD: primarily an inhibition deficit?. Archives of Clinical Neuropsychol ogy, 19(4), 569-594.

Shue, K. L., \& Douglas, V. I. (1992). Attention deficit hyperactivity disorder and the frontal lobe syndrome. Brain and cognition, 20(1), 104-124.

Schutte, N. S., Malouff, J. M., Hall, L. E., Haggerty, D. J., Cooper, J. T., Golden, C. J., \& Dornheim, L. (1998). Development and validation of a measure of emotional intelligence. Personality and individual differences, 25(2), 167-177.

Stroop, J. R. (1935). Studies of Interference in Serial Verbal Reactions. Jour nal of Experimental Psychology, 18 (6), 643-662.

Tehrani- Doost, M., Radgoodarzi., R., Sepasi, M., Alaghebandrad, J. (2003). Executive function deficits in children with attention deficit - hyperactivity. Cognitive Science News, 5 (1), 1-9.

Vinogradov, S., Fisher, M., \& de Villers-Sidani, E. (2012). Cognitive training for impaired neural systems in neuropsychiatric illness. Neuropsychopharmacology, 37(1), 43-76.

Walcott, C. M., \& Landau, S. (2004). The relation between disinhibition and emotion regulation in boys with attention deficit hyperactivity disorder. Journal of clinical child and adolescent psychology, 33(4), 772-782.

Waring, J. D., \& Kensinger, E. A. (2011). How emotion leads to selective memory: Neuroimaging evidence. Neuropsychologia, 49(7), 1831-1842.

Zeidner, M., Matthews, G., \& Roberts, R. D. (2009). What we know about emotional intelligence: How it affects learning, work, relationships, and our mental bealth. MIT press.

Zelazo, P. D., Müller, U., Frye, D., Marcovitch, S., Argitis, G., Boseovski, J., ... \& Carlson, S.M. (2003). The development of executive function in early childhood. Monographs of the society for research in child development 68, (3), 1-151. Retrieved from http://www.jstor.org/stable/1166202

(Article received: 16-02-2017; revised: 28-07-2017; accepted: 04-09-2017) 